\title{
FAKTOR-FAKTOR PENYEBAB KETERLAMBATAN PROYEK KONSTRUKSI GEDUNG KULIAH PADA MASA PANDEMI COVID 19
}

\author{
Wendi Boy $^{1 *}$, Randi Erlindo ${ }^{2}$ dan Ridho Aidil Fitrah ${ }^{3}$
}

1) Staff Pengajar Prodi Teknik Sipil Universitas Dharma Andalas Padang Sumatera Barat. email: wendi@unidha.ac.id

2) Alumni Prodi Teknik Sipil Universitas Dharma Andalas Padang Sumatera Barat, email : erlindorandi121@gmail.com

3) Staff Pengajar Jurusan Teknik Sipil Universitas Andalas Padang Sumatera Barat, email: ridho@eng.unand.ac.id

\section{Info Artikel}

Riwayat Artikel:

Dikirim : 28-04-2021

Direvisi : 15-06-2021

Diterbitkan : 28-06-2021

Keywords :

Pandemi covid 19,

faktor keterlambatan

proyek,

potensi risiko,

analisa deskriptif.

\section{ABSTRAK}

Kegiatan konstruksi pada masa pandemi covid 19 yang juga melanda Negara kita ini menjadi terbatas kegiatannya, kalaupun itu berjalan harus melakukan protokol kesehatan didalam setiap pelaksanaannya dan tentu akan berdampak kepada keterlambatan proyek tersebut. Keterlambatan dalam menyelesaikan proyek konstruksi ini akan menyebabkan kerugian baik dari pihak kontraktor maupun pihak pemilik (owner). Tujuan dari penelitian ini untuk mendapatkan faktor-faktor keterlambatan proyek konstruksi gedung pada masa pendemi covid 19. Penelitian ini mengambil sampel pada pembangunan gedung kuliah bersama Program D3 dan D4 Politeknik Pertanian Negeri Payakumbuh Sumatera Barat dengan responden seluruh pihak yang terkait didalam pembangunan tersebut baik dari owner, konsultan serta kontraktor dengan analisis yang digunakan adalah analisa deskriptif. Hasil penelitian terdapat 8 Faktor keterlambatan dengan 29 potensi risiko keterlambatan pada proyek pembangunan gedung kuliah bersama Program D3 dan D4 Politeknik Pertanian Negeri Payakumbuh Sumatera Barat dengan 5 potensi risiko tertinggi yaitu 1) kekurangan bahan konstruksi dengan nilai 4,800, 2) kontrol kontraktor utama terhadap sub-kontraktor dalam pelaksanaan pekerjaan yang memiliki nilai yang sama yaitu 4,800, 3) Komunikasi antara pekerja dan kepala tukang atau mandor dengan nilai 4,700, 4) keterlambatan pengiriman / penyedian peralatan kerja dengan nilai 4,700 dan 5) keterlambatan proses pemeriksaan dan uji bahan dengan nilai 4,700. Berdasarkan hasil penelitian ini maka disarankan agar kegiatan konstruksi pada masa pandemi Covid 19 harus lebih memperhatikan potensi-potensi risiko yang akan terjadi agar tidak menjadi kendala didalam pelaksanaan proyek konstruksi yang dapat menyebabkan keterlambatan proyek.

\section{PENDAHULUAN}

Salah satu industri yang sedang berkembang di Indonesia adalah proyek konstruksi. Peningkatan mutu dan ragam jenis infrastruktur dilaksanakan setiap tahunnya tetapi tidak semua peningkatan insfrastruktur berjalan lancar ada juga yang mengalami keterlambatan saat pembangunan proyek. Ada banyak faktor internal dan eksternal yang mempengaruhi tercapainya tujuan proyek konstruksi. Faktor-faktor yang menyebabkan keterlambatan proyek antara lain: faktor manajerial, tenaga kerja, keuangan, kebijakan pemerintah dan sebagainya. Natalia et al (2018) menemukan bahwa faktor paling dominan yang menyebabkan keterlambatan proyek di Kota Padang adalah faktor distribusi material. 
Hal-hal yang perlu diperhatikan dalam pelaksanaan proyek konstruksi yaitu biaya (cost), kualitas (quality) dan tentunya waktu (time). Pengendalian waktu harus diperhatikan karena keterlambatan penyelesaian proyek akibat tidak tepatnya waktu yang direncanakan akan sangat berpengaruh terhadap aspek lainnya yaitu biaya (cost) dan kualitas (quality). Bila suatu proyek mengalami keterlambatan penyelesaian (waktu) tentu hal ini akan berpengaruh terhadap bertambahnya biaya (cost). Keterlambatan penyelesaian proyek konstruksi ini akan menyebabkan kerugian baik dari pihak kontraktor maupun pihak pemilik (owner).

Dampak pandemi covid-19 yang mengakibatkan beberapa pekerjaan konstruksi diberhentikan sementara menjadi tertunda dan mundur dari waktu yang telah ditentukan. Namun, dengan adanya kebijakan dan perubahan yang terjadi saat ini diharapkan sektor konstruksi menjadi salah satu pendongkrak peningkatan perekonomian Indonesia pasca pandemi ini. (Buletin Konstruksi, 2020)

Kegiatan konstruksi pada masa pandemi covid 19 yang juga melanda Negara kita ini menjadi terbatas kegiatannya, kalaupun itu berjalan harus melakukan protokol kesehatan didalam setiap pelaksanaannya dan tentu akan berdampak kepada keterlambatan proyek tersebut. Keterlambatan dalam menyelesaikan proyek konstruksi ini akan menyebabkan kerugian baik dari pihak kontraktor maupun pihak pemilik (owner).

\section{METODE PENELITIAN}

Proyek konstruksi merupakan suatu rangkaian kegiatan yang saling berkaitan untuk mencapai tujuan tertentu (bangunan/konstruksi) dalam batasan waktu, biaya dan mutu tertentu. Proyek konstruksi selalu memerlukan resources (sumber daya) yaitu man (manusia), material (bahan bangunan), machine (peralatan), method (metode pelaksanaan), money (uang), information (informasi), dan time (waktu). Dalam Suatu proyek konstruksi terdapat tiga hal penting yang harus diperhatikan yaitu waktu, biaya dan mutu (Kerzner, 2006).

\subsection{Jenis-Jenis Keterlambatan Kontrak Konstruksi}

Menurut Kraiem and Diekman (1987) keterlambatan dapat dibagi menjadi 3 jenis utama, yaitu:

1. Keterlambatan yang tidak dapat dimaafkan (Non Excusable Delays). Non Excusable Delays adalah keterlambatan yang diakibatkan oleh tindakan, kelalaian, atau kesalahan kontraktor

2. Keterlambatan yang dapat dimaafkan (Excusable Delays). Excusable Delays adalah keterlambatan yang disebabkan oleh kejadiankejadian diluar kendali baik pemilik maupun kontraktor. Pada kejadian ini, kontraktor mendapatkan kompensasi berupa perpanjangan waktu saja.

3. Keterlambatan yang layak mendapat ganti rugi (Compensable Delays). Compensable Delays adalah keterlambatan yang diakibatkan tindakan, kelalain atau kesalahan pemilik. Pada kejadian ini, kontraktor biasanya mendapatkan kompensasi berupa perpanjangan waktu dan tambahan biaya operasional yang perlu selama keterlambatan pelaksanaan tersebut.

\subsection{Faktor-faktor Penyebab Keterlambatan}

Keterlambatan proyek disebabkan oleh beberapa faktor yang berasal dari Kontraktor, Owner, dan selain kedua belah pihak.

1. Keterlambatan akibat kesalah Kotraktor, antara lain :
a. Terlambatnya memulai pelaksanaan proyek.
b. Pekerja dan pelaksana kurang berpengalaman.
c. Terlambat mendatangkan peralatan.
d. Mandor yang kurang aktif.
e. Rencana kerja yang kurang baik

2. Keterlambatan akibat kesalahan Owner.
a. Terlambatnya angsuran pembayaran oleh kontraktor
b. Terlambatnya penyedia lahan
c. Mengadakan perubahan pekerja yang besar
d. Pemilik menugaskan Kontraktor lain untuk mengerjakan proyek tersebut

3. Keterlambatan yang diakibatkan selain kedua belah pihak di atas, antara lan:
a. Akibat kebakaran yang bukan kesalahan Kontraktor, Konsultan, dan Owner.


b. Akibat perang, gempa, banjir, ataupun bencana lainnya.

c. Perubahan moneter.

Pada lingkup proyek pemerintah ada beberapa faktor dominan yang mempengaruhi keterlambatan proyek kontruksi yaitu cuaca, tenagan kerja, design. Sedangkan pada lingkup proyek swasta faktor yang dominan mempengaruhi faktor keterlambatan proyek adalah cuaca material dan keuangan. (Kurniawan et al., 2018)

Keterlambatan penyelesaian pekerjaan didasari beberapa faktor antara lain tenaga kerja, bahan, karakteristik tempat, manajerial, peralatan, keuangan, fisik bangunan, disain, cuaca, kejadian tidak terduga dan kebijakan pemerintah (Wirabakti et al., 2014). Hasibuan (2014) menyatakan bahwa bahan/material merupakan salah satu factor yang mempengaruhi keterlambatan proyek kontruksi. Berdasarkan pendapat Fansuri (2014), menyatakan bahwa tenagan kerja merupakan salah satu factor yang mempengaruhi keterlambatan proyek kontruksi.

Menurut Djau dan Narasiang (2018), berdasarkan perangkingan terdapat Sembilan (9) faktor penyebab terjadinya pemutusa kontrak kerja, yaitu kerja sama tim yang buruk, hubungan kerja yang tidak harmonis dengan owner, kualitas pekerjaan rendah, kekurangan tenaga kerja, metode kerja yang tidak tepat, hubungan kerja tidak harmonis dengan supplier, kekurangan dana dalam pelaksanaan dan kegagalan kontruksi. Dari Sembilan (9) faktor tersebut terdapat empat (4) faktor penyebab terjadinya pemutusan kontrak kerja yang memiliki keeratan hubungan dengan faktor kerjasama tim yang buruk dan dapat diterima, diantaranya: pimpinan teknis tidak berpengalaman, kekurangan tenaga kerja, metode kerja yang tidak dapat dan kekurangan dana dalam pelaksanaan.

Metode penelitian yang dilakukan adalah metode survey dimana untuk informasi dikumpulkan melalui pertanyaan-pertanyaan yang disebarkan kepada responden berbentuk kuesioner. Kuesioner merupakan rangkaian atau kumpulan pertanyaan yang disusun secara sistematis dalam sebuah daftar pertanyaan untuk diisi oleh para narasumber. Pertanyaanpertanyaan yang digunakan disusun berdasarkan informasi yang diinginkan untuk memperoleh data yang berhubungan dengan pembangunan Proyek Pembangunan Gedung Kuliah Bersama Program D3 dan D4 Politeknik Pertanian Negeri Payakumbuh.

\subsection{Pengumpulan Data}

Penelitian ini dilakukan dengan Pengambilan data penyebaran link kuesioner yang telah dibuat melalui google form dan disebarkan kepada pihak Owner/PPK, Koontraktor dan Konsultan. Pengisian kuesioner yang berupa sejumlah pertanyaan mengenai Kajian-kajian yang menyebabkan keterlambatan proyek konstruksi di masa pandemi covid-19 pada proyek pembangunan gedung kuliah bersama program D3 dan D4 Politeknik Pertanian Negeri Payakumbuh. Data awal yang diperoleh digunakan pada penelitian ini meliputi data primer maupun sekunder.

Metode pengumpulan data primer dilakukan dengan cara melakukan wawancara atau diskusi, serta penyebaran kuesioner berupa gambaran bahaya dan potensi risiko kepada para responden.

1. Wawancara

Wawancara dilakukan terhadap responden dengan cara wawancara terbuka tidak terstruktur dengan tanya jawab yang berkaitan dengan risiko keterlambatan proyek.

\section{Kuesioner}

Kuesioner adalah sebuah set pertanyaan yang secara logis berhubungan dengan masalah penelitian dan tiap pertanyaan merupakan jawaban-jawaban yang mempunyai makna. Desain Kuesioner dibuat berdasarkan studi pustaka dan disesuaikan dengan studi lapangan. Struktur kuesioner terbagi dalam tiga bagian:

a. Profil responden

Berisi mengenai informasi identitas responden yaitu nama, pendidikan terakhir, umur, dan jabatan (spesifikasi pekerjaan).

b. Petunjuk pengisian kuisoner Pada bagian ini, responden diberi petunjuk pengisian kuesioner, sehingga responden tidak salah dalam pengisian jawaban kuesioner. 
c. Variabel Pertanyaan

Pertanyaan yang digunakan adalah jenis pertanyaan tertutup. Untuk mempermudah responden menjawab pertanyaan dan memfokuskan jawaban yang diharapkan.

\subsection{Tahapan Proses Pengolahan Data}

Setelah data kuesioner diuji validitas dan reliabilitas selanjutnya data kuesioner diolah sehingga diperoleh nilai rata-rata kemungkinan dan dampak dari tiap-tiap risiko. Kemudian nilai rata-rata kemungkinan dikalikan dengan nilai rata-rata dampak sehingga diperoleh nilai indeks risiko. Setelah nilai indeks risiko diperoleh, maka nilai risiko dibandingkan dengan standar level risiko untuk mengetahui rangking faktor keterlambatan.

\subsubsection{Uji Validitas Dan Uji Reliabilitas}

Setelah didapatkan hasil dari pengumpulan data yaitu berupa data probalitas dan data konsekuen hasil dari penyebaran kuesioner. Selanjutnya dilakukan uji validitas dan reliabilitas untuk mengetahui apakah hasil dari pengumpulan data yaitu penyebaran kuesioner sudah valid dan konsisten. Jika semua variabel valid maka dapat dilanjutkan dengan mengolah data.

\subsubsection{Uji Validitas}

Uji validitas adalah Mengetahui sejauh mana ketepatan dan kecermatan suatu instrumen pengukuran dalam melakukan fungsi ukurnya. Menurut Sakaran (2003) validitas menunjukkan ketepatan dan kecermatan alat ukur dalam melakukan fungsi ukurnya. Untuk menentukan tingkat kevalidan data maka diperlukan nilai $\mathrm{R}$ yang diambil dari jumlah responden. Syarat sebuah item dikatakan valid bila $r$ hitung lebih besar dari r tabel (Supranto, 2015). Rumus Uji Validitas dapat dilihat pada rumus (1).

$$
r x y=\frac{n \sum X i Y i-\left(\sum X i\right)\left(\sum Y i\right)}{\sqrt{\left(n \sum X i^{2}-\left(\sum X i\right)^{2}\right)\left(n \sum Y i^{2}-\left(\sum Y i\right)^{2}\right)}}
$$

Keterangan:

rxy $=$ Koefisien korelasi

$\mathrm{n} \quad=$ Jumlah responden uji coba

$\mathrm{X}=$ Skor tiap item

$\mathrm{Y}=$ Skor seluruh item responden uji coba

\subsubsection{Uji Reliabilitas}

Setelah uji validitas, dicek konsistensi jawaban responden melakukan uji Reliabilitas. Reliabilitas adalah sesuatu instrumen cukup dapat dipercaya untuk digunakan sebagai alat pengumpul data karena instrumen tersebut sudah baik (Arikunto, 2010). Untuk mengetahui suatu instrumen dinyatakan reliabilitas, menurut Sugiyono (2012) Suatu instrumen dinyatakan reliabel, bila koefisien reliabilitas minimal 0,60. Berdasarkan pendapat tersebut, maka diketahui bahwa suatu instrumen dinyatakan reliabel jika nilai Alpha $\geq 0,60$, sedangkan suatu instrumen dinyatakan tidak reliabel jika nilai Alpha <0,60. Rumus Uji Reabilitas dapat dilihat pada rumus (2).

$$
r 11=\left(\frac{n}{n-1}\right)\left(1-\frac{\sum \sigma t^{2}}{\sigma t^{2}}\right)
$$

Keterangan:

r11= Reliabilitas yang dicari

$\mathrm{n} \quad=$ Jumlah item pertanyaan yang di uji

$\sum \sigma t^{2}=$ Jumlah varians skor tiap-tiap item

$\sigma t^{2}=$ Varians total

\subsubsection{Rata-rata Hitung}

Dari hasil distribusi kuesioner dibuat perangkingan terhadap faktor-faktor penyebab keterlambatan pekerjaan konstruksi berdasarkan nilai mean dengan menggunakan rumus :

$$
\bar{X}=\frac{1}{n} \sum_{i=1}^{n} X_{i}
$$

Dimana:

$\bar{X}=$ mean (rata-rata) jawaban responden

$\mathrm{Xi}=$ nilai jawaban responden

$\mathrm{n}$ = banyaknya data

\section{HASIL DAN PEMBAHASAN}

\subsection{Karakteristik Responden}

Karakteristik responden merupakan ragam latar belakang yang dimiliki responden itu sendiri seperti: jenis kelamin, umur, lama bekerja, pendidikan, dan jabatan dari responden tersebut. 
Tabel 1. Jenis Kelamin

\begin{tabular}{ccc}
\hline Jenis Kelamin & Jumlah (Orang) & Persentase $(\%)$ \\
\hline Laki-Laki & 5 & 83 \\
\hline Perempuan & 1 & 17 \\
\hline Total & 6 & 100 \\
\hline
\end{tabular}

Tabel 2. Umur

\begin{tabular}{ccc}
\hline Umur & Jumlah (Orang) & Persentase $(\%)$ \\
\hline $21-30$ Tahun & 3 & 50 \\
\hline $31-40$ Tahun & 3 & 50 \\
\hline Total & 6 & 100 \\
\hline
\end{tabular}

Tabel 3. Lama Bekerja

\begin{tabular}{ccc}
\hline Lama Bekerja & Jumlah (Orang) & Persentase (\%) \\
\hline $4-10$ Tahun & 6 & 100 \\
\hline Total & 6 & 100 \\
\hline
\end{tabular}

\subsection{Hasil Uji Validitas dan Uji Reliabilitas}

\subsubsection{Hasil Uji Validitas}

Uji validitas bertujuan untuk mengukur ketepatan instrumen yang digunakan dalam suatu penelitian atau untuk melihat apakah hasil pengisian kuesioner yang dilakukan telah valid dan dimengerti oleh responden. Penentuan tingkat validitas data menggunakan nilai $R$. Penelitian ini menggunakan 4 sampel responden
Tabel 4. Pendidikan Responden

\begin{tabular}{ccc}
\hline Pendidikan & Jumlah (Orang) & Persentase (\%) \\
\hline S1 & 6 & 100 \\
\hline Total & 6 & 100 \\
\hline
\end{tabular}

Tabel 5. Jabatan Responden

\begin{tabular}{ccc}
\hline Jabatan & $\begin{array}{c}\text { Jumlah } \\
\text { (Orang) }\end{array}$ & $\begin{array}{c}\text { Persentase } \\
(\%)\end{array}$ \\
\hline Owner/PPK & 2 & 40 \\
\hline Kontraktor & 2 & 40 \\
\hline Konsultan Pengawas & 1 & 20 \\
\hline Konsultan Perencana & 1 & 100 \\
\hline Total & 6 & 100 \\
\hline
\end{tabular}

dengan taraf signifikan 5\% sehingga nilai $\mathrm{R}$ yang didapat yaitu 0,878 . Hasil uji validitas nilai $\mathrm{r}$ Hitung > r Tabel 0,878 sehingga hasil pengisian kuesioner didapatkan 19 variabel risiko yang valid dari 29 variabel risiko yang didapatkan berdasarkan penelitian-penelitian sebelumnya.

Tabel. 6. Hasil Uji Validitas

\begin{tabular}{|c|c|c|c|c|c|}
\hline $\begin{array}{c}\text { No } \\
.\end{array}$ & Faktor & Variabel (Identifikasi) Risiko & $\begin{array}{c}\text { R. } \\
\text { Hitung }\end{array}$ & $\begin{array}{c}\mathbf{R} . \\
\text { Tabel }\end{array}$ & Keterangan \\
\hline \multirow[t]{5}{*}{$\mathrm{X} 1$} & \multirow[t]{5}{*}{ Bahan (Material) } & Kekurangan bahan konstruksi X.1.1 & $.975^{*}$ & 0.811 & Valid \\
\hline & & keterlambatan pengiriman bahan X.1.2 & $.975^{*}$ & 0.811 & Valid \\
\hline & & keterlambatan prabikasi khusus bahan bangunan X.1.3 & $.973^{*}$ & 0.811 & Valid \\
\hline & & kelangkaan karena kekhususan bahan X.1.4 & $.973^{*}$ & 0.811 & Valid \\
\hline & & ketidak tepatan waktu pemesanan X.1.5 &, 345 & 0.811 & Not Valid \\
\hline \multirow[t]{5}{*}{$\mathrm{X} 2$} & \multirow{5}{*}{$\begin{array}{l}\text { Tenaga Kerja } \\
\text { (labors) }\end{array}$} & Kekurangan tenaga kerja yang berpengalaman X.2.1 & $.975^{*}$ & 0.811 & Valid \\
\hline & & $\begin{array}{l}\text { Tukang tidak mengikuti prosedur kesehatan pandemi covid- } \\
19 \text { X.2.2 }\end{array}$ & 0,567 & 0.811 & Not Valid \\
\hline & & $\begin{array}{l}\text { Jumlah pekerja yang kurang memadai dikarenakan pandemi } \\
\text { X.2.3 }\end{array}$ & $.973^{*}$ & 0.811 & Valid \\
\hline & & penggantian pekerja baru X.2.4 & 7,790 & 0.811 & Not Valid \\
\hline & & $\begin{array}{l}\text { Komonikasi antara pekerja dan kepala tukang atau mandor } \\
\text { X.2.5 }\end{array}$ & $.973^{*}$ & 0.811 & Valid \\
\hline \multirow{2}{*}{$\begin{array}{r}\mathrm{X} . \\
3 \\
\end{array}$} & \multirow{2}{*}{$\begin{array}{l}\text { Peralatan } \\
\text { (equipment) }\end{array}$} & kesulitan mencari tempat penyewaan peralatan X.3.1 & $.975^{*}$ & 0.811 & Valid \\
\hline & & keterlambatan pengiriman / penyedian peralatan kerja X.3.2 & $.973^{*}$ & 0.811 & Valid \\
\hline \multirow[t]{4}{*}{$\mathrm{X} 4$} & \multirow[t]{4}{*}{ Keuangan (financing) } & $\begin{array}{l}\text { Ketersedian keuangan selama pelaksanaan terbatas } \\
\text { (Kesulitan pendanaan di Kontraktor) X.4.1 }\end{array}$ & $.975^{*}$ & 0.811 & Valid \\
\hline & & Keterlambatan proses pembayaran oleh owner X.4.2 &, 780 & 0.811 & Not Valid \\
\hline & & Situasi perekonomian menurun X.4.3 & $.996^{* * *}$ & 0.811 & Valid \\
\hline & & $\begin{array}{l}\text { Tidak adanya uang intensif bonus) untuk kontraktor, apabila } \\
\text { waktu penyelesaian proyek lebih cepat X.4.3 }\end{array}$ & 0,789 & 0.811 & Not Valid \\
\hline \multirow[t]{2}{*}{$\mathrm{X} 5$} & \multirow[t]{2}{*}{$\begin{array}{l}\text { Lingkungan / situasi } \\
\text { (environment) }\end{array}$} & $\begin{array}{l}\text { Lingkungan proyek yang berada dikawasan zona merah } \\
\text { (covid-19) X.5.1 }\end{array}$ & $.973^{*}$ & 0.811 & Valid \\
\hline & & $\begin{array}{l}\text { Pengaruh keamanan lingkungan terhadap pembangunan } \\
\text { proyek X.5.2 }\end{array}$ & $.973^{*}$ & 0.811 & Valid \\
\hline
\end{tabular}




\begin{tabular}{|c|c|c|c|c|c|}
\hline No & Faktor & Variabel (Identifikasi) Risiko & $\begin{array}{c}\text { R. } \\
\text { Hitung }\end{array}$ & $\begin{array}{c}\text { R. } \\
\text { Tabel }\end{array}$ & Keterangan \\
\hline \multirow[t]{5}{*}{ X6 } & \multirow{5}{*}{$\begin{array}{l}\text { Lingkup dan kontrak } \\
\text { / dokumen pekerjaan } \\
\text { (contract dokument) }\end{array}$} & Keterlambatan owner dalam pembuatan keputusan X.6.1 & 0,678 & 0.811 & Not Valid \\
\hline & & $\begin{array}{l}\text { komunikasi yang kurang antara owner dengan perencana } \\
\text { pada perencanaan X.6.2 }\end{array}$ & 0,687 & 0.811 & Not Valid \\
\hline & & $\begin{array}{l}\text { perbedaan jadwal sub-kontraktor dalam penyelesaian proyek } \\
\text { X.6.3 }\end{array}$ & 0,456 & 0.811 & Not Valid \\
\hline & & $\begin{array}{l}\text { kontrol kontraktor utama terhadap sub-kontraktor dalam } \\
\text { pelaksanaan pekerjaan X.6.4 }\end{array}$ & $.975^{*}$ & 0.811 & Valid \\
\hline & & $\begin{array}{l}\text { perubahan ruang lingkup pekerjaan ( scope of works) pda } \\
\text { waktu pelaksanaan X.6.5 }\end{array}$ & $.975^{*}$ & 0.811 & Valid \\
\hline \multirow[t]{4}{*}{$\mathrm{X} 7$} & \multirow{4}{*}{$\begin{array}{l}\text { Sistem inspeksi, } \\
\text { kontrol dan evaluasi } \\
\text { (inspection, control } \\
\text { and evalution) }\end{array}$} & $\begin{array}{l}\text { Pengajuan contoh bahan oleh kontraktor yang tidak terjadwal } \\
\text { X.7.1 }\end{array}$ & $.975^{*}$ & 0.811 & Valid \\
\hline & & $\begin{array}{l}\text { proses persetujuan contoh bahan dengan waktu yang lama } \\
\text { oleh pemilik X.7.2 }\end{array}$ & 0,345 & 0.811 & Not Valid \\
\hline & & keterlambatan proses pemeriksaan dan uji bahan X.7.3 & $.975^{*}$ & 0.811 & Valid \\
\hline & & $\begin{array}{l}\text { proses dan tata cara evaluasi kemajuan pekerjaan yang lama } \\
\text { dan lewat jadwal yang disepakati X.7.4 }\end{array}$ & $.975^{*}$ & 0.811 & Valid \\
\hline \multirow[t]{2}{*}{$\mathrm{X} 8$} & \multirow{2}{*}{$\begin{array}{l}\text { Manajerial } \\
\text { (managerial }\end{array}$} & Komunikasi antara perwakilan pemilik dan kontraktor X.8.1 & $.975^{*}$ & 0.811 & Valid \\
\hline & & komunikasi antara perencana dan kontraktor X.8.2 & & & \\
\hline
\end{tabular}

\subsubsection{Hasil Uji Reabilitas}

Menurut Sugiyono (2012) dalam Boy et al (2017) Suatu instrumen dinyatakan reliabel, bila koefisien reliabilitas minimal 0,60. Artiya suatu instrumen dinyatakan reliabel jika nilai Alpha $\geq$ 0,60, hasil uji reliabilitas nilai Cronbach's Alpha $>$ Alfa 0,6 sehingga dinyatakan memiliki reliabilitas yang tinggi. Nilai Cronbach's Alpha $=0,993>0,600$ maka dapat disimpulkan hasil kusioner memiliki data yang realibel. Hasil pengujian reliabilitas dapat dilihat pada Tabel 7 berikut ini:
Tabel 7. Reliabilitas

\begin{tabular}{|cc|}
\hline \multicolumn{2}{|c|}{ Reliability Statistics } \\
\hline Cronbach's Alpha & N of Items \\
\hline, 993 & 29 \\
\hline
\end{tabular}

\subsubsection{Rangking Faktor-faktor Risiko Keterlambatan Proyek}

Berdasarkan analisa deskriptif rata-rata dari faktor-faktor risiko keterlambatan proyek konstruksi pada masa Pandemi Covid-19 dari jawaban responden didapatkan rangking seperti pada Tabel 8 berikut ini :

Tabel 8. Rangking Faktor- Faktor Risiko Keterlambatan Proyek Konstruksi pada Masa Pandemi Covid-19

\begin{tabular}{|c|c|c|c|}
\hline No. & Faktor & Variabel (Identifikasi) Risiko & $\begin{array}{l}\text { Nilai } \\
\text { Risiko }\end{array}$ \\
\hline 1 & Bahan (Material) X.1 & Kekurangan bahan konstruksi X.1.1 & 4,800 \\
\hline 2 & $\begin{array}{l}\text { Lingkup dan kontrak / dokumen } \\
\text { pekerjaan (contract document) X.6 }\end{array}$ & $\begin{array}{l}\text { kontrol kontraktor utama terhadap sub-kontraktor dalam pelaksanaan } \\
\text { pekerjaan X.6.4 }\end{array}$ & 4,800 \\
\hline 3 & Tenaga kerja (labors) X.2 & Komunikasi antara pekerja dan kepala tukang atau mandor X.2.5 & 4,700 \\
\hline 4 & Peralatan (equipment) X.3 & Keterlambatan pengiriman / penyedian peralatan kerja X.3.2 & 4,700 \\
\hline 5 & $\begin{array}{l}\text { Sistem inspeksi, kontrol dan evaluasi } \\
\text { (inspection, control and evalution)X.7 }\end{array}$ & Keterlambatan proses pemeriksaan dan uji bahan X.7.3 & 4,700 \\
\hline 6 & Bahan (Material) X.1 & Keterlambatan pengiriman bahan X.1.2 & 4,500 \\
\hline 7 & Bahan (Materal) X.1 & Keterlambatan pabrikasi khusus bahan bangunan X.1.3 & 4,500 \\
\hline 8 & Tenaga Kerja (labors) X.2 & Jumlah pekerja yang kurang memadai dikarenakan pandemi X.2.3 & 4,500 \\
\hline 9 & Keuangan (financing) X.4 & $\begin{array}{l}\text { Ketersedian keuangan selama pelaksanaan terbatas (Kesulitan pendanaan } \\
\text { di Kontraktor) X.4.1 }\end{array}$ & 4,500 \\
\hline 10 & Manajerial (managerial) X.8 & Komunikasi antara perwakilan pemilik dan kontraktor X.8.1 & 4,500 \\
\hline 11 & Keuangan (financing) X.4 & Situasi perekonomian menurun X.4.3 & 4,300 \\
\hline 12 & Bahan (Material) X.1 & Ketidak tepatan waktu pemesanan X.1.5 & 4,200 \\
\hline 13 & Peralatan (equipment) X.3 & Kesulitan mencari tempat penyewaan peralatan X.3.1 & 4,200 \\
\hline 14 & Bahan (Material) X.1 & Kelangkaan karena kekhususan bahan X.1.4 & 4,000 \\
\hline 15 & Tenaga Kerja (labors) X.2 & Kekurangan tenaga kerja yang berpengalaman X.2.1 & 4,000 \\
\hline 16 & Lingkungan / situasi (environment) X.5 & Lingkungan proyek yang berada dikawasan zona merah (covid-19) X.5.1 & 4,000 \\
\hline
\end{tabular}




\begin{tabular}{|c|c|c|c|}
\hline No. & Faktor & Variabel (Identifikasi) Risiko & $\begin{array}{l}\text { Nilai } \\
\text { Risiko }\end{array}$ \\
\hline 17 & $\begin{array}{l}\text { Lingkup dan kontrak / dokumen } \\
\text { pekerjaan (contract document) X.6 }\end{array}$ & Perbedaan jadwal sub-kontraktor dalam penyelesaian proyek X.6.3 & 4,000 \\
\hline 18 & $\begin{array}{l}\text { Sistem inspeksi, kontrol dan evaluasi } \\
\text { (inspection, control and evalution)X.7 }\end{array}$ & Pengajuan contoh bahan oleh kontraktor yang tidak terjadwal X.7.1 & 4,000 \\
\hline 19 & $\begin{array}{l}\text { Sistem inspeksi, kontrol dan evaluasi } \\
\text { (inspection, control and evalution)X.7 }\end{array}$ & $\begin{array}{l}\text { Proses dan tata cara evaluasi kemajuan pekerjaan yang lama dan lewat } \\
\text { jadwal yang disepakati X.7.4 }\end{array}$ & 4,000 \\
\hline 20 & Tenaga Kerja (labors) X.2 & Tukang tidak mengikuti prosedur kesehatan pandemi covid-19 X.2.2 & 3,800 \\
\hline 21 & Lingkungan / situasi (environment) X.5 & Pengaruh keamanan lingkungan terhadap pembangunan proyek X.5.2 & 3,800 \\
\hline 22 & $\begin{array}{l}\text { Lingkup dan kontrak / dokumen } \\
\text { pekerjaan (contract document) X.6 }\end{array}$ & $\begin{array}{l}\text { Perubahan ruang lingkup pekerjaan ( scope of works) pda waktu } \\
\text { pelaksanaan X.6.5 }\end{array}$ & 3,300 \\
\hline 23 & Tenaga Kerja (labors) X.2 & Penggantian pekerja baru X.2.4 & 3,200 \\
\hline 24 & $\begin{array}{l}\text { Sistem inspeksi, kontrol dan evaluasi } \\
\text { (inspection, control and evalution)X.7 }\end{array}$ & $\begin{array}{l}\text { Proses persetujuan contoh bahan dengan waktu yang lama oleh pemilik } \\
\text { X.7.2 }\end{array}$ & 3,200 \\
\hline 25 & Keuangan (financing) X.4 & Keterlambatan proses pembayaran oleh owner X.4.2 & 2,500 \\
\hline 26 & $\begin{array}{l}\text { Lingkup dan kontrak / dokumen } \\
\text { pekerjaan (contract document) X.6 }\end{array}$ & $\begin{array}{l}\text { komonikasi yang kurang antara owner dengan perencana pada } \\
\text { perencanaan X.6.2 }\end{array}$ & 2,000 \\
\hline 27 & Manajerial (managerial) X.8 & komonikasi antara perencana dan kontraktor X.8.2 & 2,000 \\
\hline 28 & $\begin{array}{l}\text { Lingkup dan kontrak / dokumen } \\
\text { pekerjaan (contract document) X.6 }\end{array}$ & Keterlambatan owner dalam pembuatan keputusan X.6.1 & 1,700 \\
\hline 29 & Keuangan (financing) X.4 & $\begin{array}{l}\text { Tidak adanya uang intensif bonus) untuk kontraktor, apabila waktu } \\
\text { penyelesaian proyek lebih cepat X.4.3 }\end{array}$ & 1,500 \\
\hline
\end{tabular}

\section{KESIMPULAN}

Berdasarkan hasil analisis, maka dapat diberikan kesimpulan sebagai berikut :

1. Dari hasil penelitian teridentifikasi 19 potensi risiko yang terjadi pada proyek pembangunan gedung kuliah bersama Program D3 dan D4 Politeknik Pertanian Negeri Payakumbuh Sumatera Barat.

2. Dari hasil analisis penilaian data diperoleh dua faktor dan variabel penyebab keterlambatan proyek dengan nilai rata-rata tertinggi yaitu Faktor Bahan dengan variabel risiko yaitu: Kekurangan Bahan Konstruksi dengan nilai rata-rata 4,800 dan Faktor Lingkup dan Kontrak / Dokumen Pekerjaan dengan variabel risiko yaitu kontrol kontraktor utama terhadap sub-kontraktor dalam pelaksanaan pekerjaan dengan nilai yang sama yaitu: 4,800 .

\section{UCAPAN TERIMA KASIH}

Ucapan terima kasih kepada pihak-pihak terkait yang telah membantu penelitian ini yaitu: PPK, Kontraktor, Konsultan Perencana dan Konsultan Pengawas Proyek Pembangunan Gedung Kuliah Bersama Program D3 dan D4 Politeknik Pertanian Negeri Payakumbuh, serta pihak-pihak yang tidak dapat disebutkan satu persatu.

\section{DAFTAR PUSTAKA}

Arikunto, S. (2010). Prosedur Penelitian Suatu Pendekatan Praktik. Jakarta: Rineka Cipta.
Boy, W., Suripin, S., \& Wibowo, M. A. (2017). Construction risk management model of housing reconstruction basing the community after earthquake disaster. International Journal of Civil Engineering and Technology, 8(10), 1220-1236. https://www.scopus.com/inward/record.uri? eid=2-s2.0-85032633202\&partner ID $=40 \&$ md5=ae632119d510a287a09b269cb2af1f03

Direktorat Jenderal Bina Konstruksi Kementerian Pekerjaan Umum dan Perumahan Rakyat. (2020). Buletin Konstruksi (Edisi 4). Jakarta Selatan.

http://binakonstruksi.pu.go.id/jdownloads/B uletin/Buletin_2020/Buletin_Konstruksi_4 20.pdf

Djau, R. A., \& Narasiang, B. S. (2018). Identifikasi Faktor-Faktor Penyebab Terjadinya Pemutusan Kontrak Kerja Pada Proyek Pembangunan Masjid Kompleks Blok Plan Tahap I Kabupaten Gorontalo Utara. Jurnal Tekno, 16(69). https://ejournal.unsrat.ac.id/index.php/tekno /article/view/20909

Fansuri, S. (2014). Penyebab Terjadinya Keterlambatan Waktu Penyelesaian Proyek Kontruksi. Jurnal Media Informasi Teknik Sipil Unija (MITSU), 2(2), 7-14. https://doi.org/10.24929/ft.v2i2.87 
Hasibuan, K., Hidayat, A., \& Lumba, P. (2014). Analisa Manajemen Terhadap Faktor Keterlambatan Proyek Kontruksi di lingkungan Dinas Pariwisata Kabupaten Rokan Hulu. Jurnal Mahasiswa Teknik Universitas pasir Pengaraian, 1(1). https://media.neliti.com/media/publications/ 110443-ID-analisis-manajemen-terhadapfaktor-keter.pdf

Kerzner, H. (2006). Project Management; A System Approach to Planning, schedulling, and controlling. John and Wiley. Inc. Ninth Edition. New Jersey.

Kraiem, Z. K., \& Diekman, J. E. (1987). Concurent Delays in Construction Projects. Journal of Construction Engineering and Management, ASCE, 113(4), 591-602.

Kurniawan, F., Wulandari, D. A. R., \& Ayu, L. A. (2018). Studi Kasus Keterlambatan Proyek Konstruksi Di Provinsi Jawa Timur Berdasarkan Kontrak Kerja. 2(2): 21-31. Narotama Jurnal Teknik Sipil (Universitas Narotama), 2(2). 21-31.

https://doi.org/10.31090/njts.v2i2.698
Natalia, M., Riswandi, Mirani, Z., Partawijaya, Y., \& Misriani, M. (2018). Faktor Penyebab Kegagalan Akibat Keterlambatan Proyek Konstruksi pada Bangunan Gedung di Kota Padang. Jurnal Ilmiah Rekayasa Sipil (Politeknik Negeri Padang), 15(2), 24-36. https://doi.org/10.30630/jirs.15.2.129

Sekaran, U. (2003). Research Methods for Business: A Skill Building Aproach, New York-USA: John Wiley and Sons, Inc.

Sugiyono. (2012). Statistika untuk Penelitian. Bandung: Penerbit Alfabeta.

Supranto, J. (2015). Statistik Untuk Pemimpin Berwawasan Global. Jakarta: Salemba Empat,

Wirabakti, D. M., Abdullah, R., \& Maddeppungeng, A. (2014). Studi FaktorFaktor Penyebab Keterlambatan Proyek Konstruksi. Jurnal Konstruksia, 6(1), 15-29. https://jurnal.umj.ac.id/index.php/konstruks ia/article/viewFile/283/259 